\title{
Intellectual Failure and Ideological Success in Organization Studies
}

\section{The Case of Transformational Leadership}

Alvesson, Mats; Kärreman, Dan

\author{
Document Version \\ Accepted author manuscript \\ Published in: \\ Journal of Management Inquiry \\ DOI: \\ $10.1177 / 1056492615589974$ \\ Publication date: \\ 2016 \\ License \\ Unspecified
}

Citation for published version (APA):

Alvesson, M., \& Kärreman, D. (2016). Intellectual Failure and Ideological Success in Organization Studies: The Case of Transformational Leadership. Journal of Management Inquiry, 25(2), 139-152.

https://doi.org/10.1177/1056492615589974

Link to publication in CBS Research Portal

\section{General rights}

Copyright and moral rights for the publications made accessible in the public portal are retained by the authors and/or other copyright owners and it is a condition of accessing publications that users recognise and abide by the legal requirements associated with these rights.

\section{Take down policy}

If you believe that this document breaches copyright please contact us (research.lib@cbs.dk) providing details, and we will remove access to the work immediately and investigate your claim. 


\title{
Intellectual Failure and Ideological Success in Organization Studies: The Case of Transformational Leadership
}

\author{
Mats Alvesson and Dan Kärreman \\ Journal article (Post print version)
}

This article was originally published in:

Journal of Management Inquiry

First published online: 24 June 2015

DOI: $10.1177 / 1056492615589974$

Uploaded to Research@CBS: November 2015

Available at:

http://research.cbs.dk/da/publications/intellectual-failure-and-ideologicalsuccess-in-organization-studies\%28bf92703a-32b0-4fc0-9db2-

52ec8fa64953\%29.html 
This paper engages with the role of ideology in scientific success. Our case in point is the peculiar success of transformational leadership research in leadership studies. We have chosen this case for several reasons. Leadership studies are considered to be an important field with a lot of research activity. For a long time it was viewed by many as close to failure. For instance, Sashkin \& Garland (1979) claimed that: 'By any objective measure, the study of leadership has failed to produce generally accepted, practically useful, and widely applied scientific knowledge' (p. 65). Another review of the research pessimistically concluded that 'the only point of agreement is that existing approaches have largely lost their usefulness for the further development of the field' (Andriesen \& Drenth, 1984 p. 514).

However, the last three decades have demonstrated a considerable consolidation of ideas, epitomised in the idea of transformational leadership. In this sense, advocates of transformational leadership (TFL) market the approach as an unequivocal example of scientific success, despite fundamental flaws (van Knippenberg \& Sitkin, 2013; Yukl, 1999). Bryman (1996) allocates the 'much greater optimism' to the shift of leadership towards 'management of meaning and a recognition of a greater range of research styles' (p 289). Avolio et al (2003 277) noted that earlier at conferences people sometimes remarked that 'never has a construct been studied so much that we know so little about' but that such opinions now are both obsolete and wrong. Parry \& Bryman (2006 p. 464) add that negative remarks are 'unlikely to be heard nowadays' and emphasize how 'exciting and productive field that leadership has become'.

Most of the optimism is associated with the amazing 'success' of transformational leadership (TFL) and other positive-sounding leadership versions, like charismatic, servant and authentic leadership or emotional intelligence as a key element in good leadership. 
TFL is often perceived to have 'generated an impressive cachet of findings and has made a great impact on the study of leadership' (Jackson \& Parry, 2008 p. 31).

The first aim with this paper is to explore how we can understand the boosting of leadership and the perceived success, including of its leading stream, TFL, and its overlapping or related approaches, despite these being quite problematic in terms of realism and thus being questionable in terms of both descriptive and normative (practical) value. The move from the perception of failure to a sense of great success and optimism of academic leadership studies over a decade or so can be seen as a mystery in need for an explanation (Alvesson \& Kärreman, 2011). How has this quantum leap from a broad sense of misery to one of great enthusiasm and success been accomplished? It can't be taken for granted that it is the intellectual qualities, as carefully monitored by a critically minded research community (Bernstein, 1983) that accounts for the perceived success of leadership studies (LS). To the contrary, we argue for the opposite: it is rather the bracketing of such qualities that have facilitated the success.

A second aim is to offer a critique of the ideological overtones of the most influential forms of contemporary leadership studies and argue for a more open-minded view of leadership. Overall, our contribution is to show how ideology is built into research design and thus prestructures outcomes and suggest ways of 'de-ideologizing' leadership. The focus of this paper is the academic leadership approaches that articulate appealing views of successful leadership. We pay particular attention to the case of transformational leadership.

\section{Ideology in organization and leadership studies}


Ideology is a widely used concept in social science, sometimes pejoratively (in an older Marxist tradition) used to refer to false beliefs covering up a dominant social order, sometimes viewed more neutrally as a system of ideas and values (Freeden, 2003; Hartley, 1983). Geertz (1973) distinguishes between an interest and a strain theory of ideology, where the interest theory uses the concept of ideology to explain a group's search for power, while the strain view considers ideology as a means to reduce stress and anxiety due to lack of cultural resources (see also Kunda, 1992).

The concept of ideology is sometimes, but not so frequently used in organization studies, sometimes critically (Alvesson, 1987; Alvesson \& Willmott, 2012), sometimes less so (Barley \& Kunda, 1992; Czarniawska-Joerges, 1988; Kunda, 1992). Surprisingly, but also perhaps tellingly, ideology is rarely evoked in leadership studies (Holmberg \& Strannegård (2006) and Vangen \& Huxham, (2003) are exceptions). We may think of leadership as an inherently ideological activity, but this idea is rarely committed to serious study.

In this paper we use ideology to refer to the painting of a positive and appealing picture, legitimising certain interests and a specific social order (Alvesson, 1987). Ideology also offers avenues for decontestation (Freeden, 2003) - making essentially contestable concepts less contentious. In this sense, ideology is a device to cope with ambiguity and the indeterminacy of meaning. Ideology orders, patterns and suppress surplus meaning. An ideology may have many effects: legitimation, portraying reality in a brighter light, inserting hope, offering ideals worth striving for (Alvesson, 1987). It offers clarity and comprehension. It offers identity material for managers (and other leader-wannabes, like 
students), where the mundane, instrumental and operative sides of managerial work are forgotten in favour of far more impressive and ego- and status-boosting activities.

Rather than being a bastion against ideology, a so called scientific methodology may reproduce and reinforce it. All social scientists have good reasons to address how ideological commitments and ambitions to support certain 'good' causes may guide and sometimes counteract open inquiry and qualified understandings. We pay specific attention in this paper to how ideology imprints the research design and guides the production of for the researchers advocating TFL theory favorable data. We show that behind the production of seemingly reliable results the ideological construction of data is at play. The next section of this paper will review leadership research in broad terms. We will pay particular attention to the emergence of TFL, and critically review its main claims. A discussion on the role of ideology in TFL, and in research in general follows, with some concluding suggestion on potential remedies.

\section{Transformational leadership: what it is and why it is problematic}

Transformational leadership (TFL) is often equated with effective leadership. It is the theoretical flagship in the great armada of the booming area of leadership - also including authentic, charismatic, self and many other versions of leadership, much of this is (or was) summarized as 'new leadership' (Bryman 1996), but the label is perhaps a bit dated by now. All these streams making up 'the new' can be seen as broadly similar or fairly distinct. Various authors for example see transformational and charismatic leadership as the same (van Knippenberg \& Sitkin, 2013), similar/overlapping (Sashkin, 2004), as siblings (Jackson \& Parry, 2008) or as quite different (Yukl, 1999). This implies some 
vagueness and confusion. Despite this, they are seen as key and related parts of a highly influential leadership research field.

TFL is often seen as being about how leadership accomplishes something really extraordinary:

'leaders transform followers. That is, followers are changed from being self-centered individuals to being committed members of a group' (Sashkin, 2004 p. 175).

There are different views of what TFL includes (Sashkin, 2004), but typically individualized consideration, intellectual stimulation, idealized influence (charisma) and inspirations are seen as ingredients. TFL advocates assume that the so-called leader has significant influence on followers' self-confidence, enthusiasm, identification with the group/organization and voluntary compliance. The leader stands for agency while follower agency, as well as social conditions, do not matter much. The literature is full of strong claims about the grandiose accomplishments of TFL, e.g. 'transformational leaders connect followers' self-concepts to the organization's mission and vision ...' (Hartnell \& Wallumbwa, 2011 p. 232)

Despite its popularity, TFL has, until recently, only to a limited degree been exposed to critique. In a review article Diaz-Saenz (2011) mentions idealization of leadership, technical issues around measurements, insufficient attention to context and misunderstanding of charisma. The most prominent critique has been offered by Yukl (1999) and Van Knippenberg \& Sitkin (2013). Yukl (1999) points at ambiguity about underlying influence process, overemphasis on dyadic processes, ambiguity about transformational behaviours, insufficient specification of negative effects and heroic 
leadership bias. Van Knippenberg \& Sitkin (2013) echo many of these points, summarizing their critique as follows:

'The conceptualization of the construct is seriously flawed, with no definition of charismatic-transformational leadership independent of its effects, no theory to explain why it consists of the dimensions proposed and how these dimensions share a charismatic-transformational quality that differentiates them from other aspects of leadership, and no theoretically grounded configurational model to explain how the different dimensions combine to form charismatic-transformational leadership.' ( $p$ 45)

Below we build upon and expand parts of the critique, making the case that the 'success' of TFL - and also leadership studies as a whole - is not primarily a matter of its scientific qualities in terms of theoretical clarity or empirical support, but is related to its ideological appeal and how this has been built into research design, leading to attractive 'findings'.

Incoherent constructs. A major problem is the arbitrary and incoherent combination of the key elements in TFL . One example is charisma and TFL. As Yukl (1999) points out, 'the developing and empowering behaviours associated with TFL seem to make it less likely that followers will attribute extraordinary qualities to the leader' (p 299). Also, why should idealized influence, inspirational motivation, intellectual stimulation and individualized consideration co-exist? It appears unlikely that these four typically should go together in a leader’s behaviour or 'style' (Van Knippenberg \& Sitkin, 2013).

Arbitrary exclusion. One may also wonder why certain things are not on the various lists of TFL traits and behaviours. Yukl (1999) mentions for example facilitating agreements about objectives and strategies, mutual trust and cooperation and building group identification as important group level work as well as articulating a vision and strategy for the organization, guiding and facilitating change and promoting learning at the organizational 
level as important behaviours typically omitted from many TFL transformational behaviours lists..

Leader-centricism. Often TFL - and many other leadership theories - embrace what could be referred to as the sheep view on managing. The leader leads, the others follow almost mindlessly and without much will or ability. The idea is that the TFL person is the centre of the organizational universe and has far reaching impact. As leadership is about influencing processes then how those who are supposedly influenced understand and respond to the intentions and behaviour of the manager appears to be central. However, the interest in taking this really seriously appears to be weak, with the exception of the follower-centric literature (e.g. Meindl, 1995; Howell \& Shamir, 2005; Uhl-Bien \& Pillai, 2007).

Denial/minimization of social setting. Most of the popular leadership ideas assume the existence of the sole leader forming a stable and robust entity with fixed traits and skills operating on others being shaped and improved as a function of the leader's essence being put into operation. Context is regularly neglected (Fairhurst 2001). An illustration is that only three of eight influential views of TFL reviewed by Sashkin (2004) actually explicitly see context as part of the picture, and then mainly as organizational culture being something that the TFL creates or controls.

Disregard for social dynamics. A key characteristic such as 'communicating a vision' is typically seen as the TFL developing and communicating the 'vision', others receiving and being transformed by it. This fails to take into account that organizations are full of communications and influence processes in all directions. One study found that managers 
viewed their subordinates - not their superiors - as their most significant source of feedback (Kairos Futures/Chef 2006). Researchers have rarely addressed the issue of how managers and subordinates influence each other (Liden \& Antonakis, 2009).

Tautology in description and explanation. We also have the more fundamental problem of tautology where input and output are simply combined; where a behaviour, ability or practice is defined by the effects it creates. A person that is said to be into work that 'Empowers and develops potential', and is an 'Inspirational networker and promoter' (Alimo-Metcalfe \& Alban-Metcalfe, 2001) must per definition be better than one that dispowers, does not develop (but hinders) potential, and is un-inspiring. Someone offering intellectual stimulation or inspirational motivation in a managerial/leadership position is surely better than someone that does not. Someone assessed to have 'extraordinary' qualities will probably not be assessed as having poor results.

Do good-ism. Many efforts to specify good leadership say rather little specifically about the topic: often the list of characteristics/dimensions would seem to indicate success for any person doing honourable work - as professional or even as subordinate. Jackson \& Parry (2008) believe that qualities like confidence, integrity, connection, resilience and aspiration 'are particularly effective to promote effective leadership' (p 17). The list of factors being part of TFL by Alimo-Metcalfe \& Alban-Metcalfe (2001) include genuine concern for others, empowers and develop potential, integrity, trustworthy, honest and open, accessibility and approachability. Of course, this sounds really good and most people may want this from their nurse, therapist, teacher and brother-in-law as much as from their manager - or their subordinate. 
To sum up, popular and influential descriptions of leadership such as TFL and related streams show several weak spots. One would assume that any serious academic subject would critically address these issues. Not surprisingly, there are considerable efforts to develop alternative approaches, e.g. discursive approaches (Fairhurst, 2007; Kelly, 2008), relational theory (Uhl-Bien, 2006), follower-centred approaches (Meindl, 1995; Uhl-Bien \& Pillai, 2007), dialogic, developmental, dialectical and critical understandings (Collinson, 2005, 2011; Fryer, 2011, Helsing \& Howell, 2014 Latham, 2014) as well as management of meaning/sense-making versions without the strong emphasis on the transformational impact of the leader (Smircich \& Morgan, 1982; Ladkin, 2010). But also many 'nonheroic' views express a strong emphasis of leadership as 'good-doing'. Ospina and Sorensen (2006 p. 188) suggest 'that leadership happens when a community develops and uses, over time, shared agreements to create results that have collective value'. Uhl-Bien el al. (2007 p. 298) frame 'leadership as a complex, interactive dynamic from which adaptive outcomes (e.g. learning, innovation, and adaptability) emerge'. Leadership is defined by its good outcomes.

The mentioned 'alternative' views are considered to be outside of mainstream TFL, charismatic and authentic leadership studies and they should not divert attention from the key point of this paper: understanding the 'success' of the leadership field as dominated by TLF and similar formulations, despite their obvious flaws. Arguably, much of what is published under the label of leadership contributes to strengthen, rather than undermine, the ideology of leadership legitimizing and supporting a faith in leader-elites doing the good thing. Many researchers find a market for work using the popular signifier 'leadership' because TFL and other mainstream approaches have made leadership fashionable. 
Many efforts to develop 'alternative' views thus at the same time partly break with and reinforce the domination of 'leadership' (Alvesson \& Spicer, 2014). Nuances involved in the efforts to revise 'leadership' are easily lost as the major framing reinforces a dominating 'mega-discourse', weakening others. For example, this reinforces an understanding that the alternative to leadership is leadership, not peer relations, professionalism, autonomy, co-workership, organizing processes or mutual adjustment offering alternative framings and understanding than what the leadership vocabulary invites to.

\section{The ideological content of leadership studies: heroes and saints}

If the theoretical value of streams like TFL and all the empirical studies demonstrating support for it is less than impressive, how can we understand their popularity? We argue that contemporary leadership ideas offer two contributions of a broadly speaking ideological and, for managers and (other) leader-wannabes, identity-boosting nature: the fuelling of hero and saint fantasies.

Drawing on Geertz's (1973) distinction between types of ideology, there is both an interest and a strain-reducing element in our argument. Managers, management writers and educators use leadership in an ideological way to promote their interests and, simultaneously, evoke a broad attribution of faith in positive forms of leadership leading to harmony, effectiveness and moral order. Ideology in the context of leadership suggests that managers and others positively disposed to leadership use the term in order to build and maintain a positive, celebrating, even glamorous view of organizational relations, 
naturalizing and freezing (asymmetrical) social relations. Leadership as ideology is framed in ways that are seductive and easy to sell

There is a critical element in this view, pointing out that the seemingly neutral science of leadership denies the ideological element. But ideology does not refer to false consciousness - the distinction between false and true consciousness seems dated and difficult to maintain. Rather it is about the tendency to paint leadership in pink and gold, or as observed by Spoelstra \& ten Bos (2011): 'leadership scholars generally produce all sorts of beautiful images of leadership' ( $p$ 182). The domination of this morally reassuring view of leadership discourages us from exploring the contradictions and problems within leadership discourse. ${ }^{1}$

In research guided by ideological commitments, the ideal 'structures observations so thoroughly that researchers come to actually believe that they are observing harmonious systems' (Fleming \& Mandarini, 2009 p. 331). All the good things go in hand and the not so good is marginalized and demonized as 'toxic', inauthentic leadership or not really leadership but something else, e.g. tyranny (Jackson \& Parry, 2008). 'True leadership' is 'good'. Here invoking transaction leadership (really referring to management) 'as the dull, mechanical, carrots-and-sticks leadership that would be more ordinary and customary (forms) a background against which charismatic-transformational leadership shines all the more brightly.' (Van Knippenberg \& Sitkin, 2013 p. 12)

\footnotetext{
${ }^{1}$ We should of course also consider the opposite tendency, an inclination to paint the world in grey and black, common in critical work that sometimes draw upon an ideology of free, equal members of a happy community not in need of managers and leaders. Our paper may be read as ideological in this sense. Our purpose is not, however, to deny the value of senior people exercising leadership, but to point to some serious problems of dominant ideas on leadership as exemplified by TFL as part of an effort to understand the transition of LS from perceived failure to perceived success and then question the latter. The ideology of TFL - not the ideology of (the small group of) critical scholars - is here in focus.
} 
Hero-worship and other forms of leadership celebration

In much influential leadership there is an undertone of heroic mythology - where heroic individuals of true grit get followers in shape and performing as the leader intends. Of course this is most obvious in all the pop-management and Harvard Business Review-type writings targeting the mass market were the sole founder or CEO of a firm makes the big difference (e.g. Collins, 2001), but it also frames many academic leadership studies of today. LS people seem to have seen too many John Wayne movies.

Leadership is, within the leadership ideology, viewed as crucial, also in cases where the extreme hero-worshipping is avoided. We always are told things such as 'a leader is responsible for direction, protection, orientation, managing conflict and shaping norms' (Heifetz \& Laurie, 1994 p. 127). This may sound uncontroversial, but the statement implies that others are not responsible for, and in need of, direction, protection, orientation, etc (Blom \& Alvesson, 2014). Perhaps 'non-leaders' often can take responsibility for and are not in need of direction, protection, etc. But this possibility is marginalized in the most influential leadership theories. Also in knowledge-intensive, innovative contexts - where one would assume non-managers to be competent professionals, capable of autonomy and initiative - leadership authors emphasize an almost endless number of tasks and functions for leaders to do (Mumford et al, 2002). More generally, non-leaders are often reduced to objects or recipients of the leader's impressive acts:

'leaders instill their values, beliefs, and assumptions within an organization' (Hartnell \& Wallumbwa, 2011 p. 232) 
Before or without the Leader, there were uncertainty, bewilderment, chaos, selfishness; after or with the Leader the confused get direction, the weak become confident, the egoistic or shortsighted can now see the light (the vision). The heroic template is here, copied and slightly transformed so that it fits into the academic leadership genre. All the powerful influence of the leader calls for a larger than life character - appealing more to fantasy and wishful thinking than a realistic view of what a manager in an organization can be and accomplish. Leadership researchers produce long lists of impressive things that leaders should do for and with their subordinates (e.g. Mumford et al, 2002), including an ability to 'define the parameters of the corporate culture' (Kets de Vries, 1994 p. 78; see also Hartnell \& Wallumbwa, 2011; Sashkin, 2004; Schein, 1985 and others seeing leaders as heroic culture creators). Compared to earlier times more modest views of leadership often emerging from studies of supervisors - contemporary ideas of leadership are much more grandiose (Alvesson, 2013).

The heroic template for how to deal with the hardships of the world offers support for managers and others in contemporary bureaucracies in terms of day-dreaming and fantasies and, thereby, more favourable identity constructions. Somehow leadership is supposed to introduce extra-ordinary qualities into organizations. This ingredient is also present in so called post-heroic leadership, where ideas such as shared or distributed leadership are mainly a matter of the re-phrasing of teamwork or mutual adjustment, but where the signifier 'leadership' is used, arguably in order to have more appeal (e.g. Gronn, 2002; Pearce \& Conger, 2003). Through labeling team work and mutual adjustment 'leadership', there is a minor element of heroization of peer relations and any form of influencing act. Here everybody can do leadership - nobody is supposed to do followership. How organizations are supposed to work and all the carrying out of tasks 
calling for compliance is supposed to be done is conveniently left aside. An appealing and positive view full of the good things associated with leadership thus dominates and basic contradictions are denied.

We can here see how ideology is not only, as in case of TFL and other leadership celebrating approaches reach peak levels, but also is broadly distributed to cover almost all aspects of organizational life, ranging from strongly heroic versions to alternative, 'postheroic' ones were still everybody, in principle, get a sprinkle of the glamour of being portrayed as being a leader or involved in leadership (and not just a self-going employee or a peer).

\section{Saint-canonization}

But just being powerful or adding strong individual qualities like transforming the selfish or confused into altruistic and self-confident organizational members is not sufficient. Powerful individuals may be bad, indeed with a strong power position it is probably easy to loose ground contact - feedback may be weaker and narcissism may flourish, leading to a less well-functioning moral compass (Kets de Vries, 1980).

Much leadership studies have a strong religious, messianic overtone (Alvesson, 2011; Spoelstra \& ten Bos, 2011; Tourish \& Pinnington, 2002), often overlapping with hero qualities, but authenticity can also be addressed without directly invoking heroism in the sense of powerful action and heroes don't have to exhibit transparency. Reassurance of the qualities of our elites - in a time full of moral uncertainty, doubt and worries leadership ideas offers us comfort. Leaders, at least those deserving to be seen as 'real' leaders, are 
not only powerful, they are powerful in a moral way. Effective leadership is for example married with integrity - as Palanski \& Yammarino (2009) write, this is almost an axiom in leadership studies. If leaders are power-oriented, it is only for the good of the organization. Good leaders are authentic; they have integrity and a sense of moral purpose making them capable of increasing the moral standards of followers. If people in powerful positions are not of true grit, they are not really leaders, but something else: tyrants, inauthentic, managers and so on (Burns, 1978; Jackson \& Parry, 2008).

Bass and Steidlmeier (1999), who according to Parry \& Bryman (2006 p. 453) have partly rectified the problem of insufficient attention to the negative aspects of TFL, distinguish between authentic and pseudo-transformational leadership. This is not a matter of behaviour per se, but rather the noble respectively murky motives driving the leader. The authentic leader focuses on universal values, addresses real threats and develops followers into leaders, while the pseudo TFL highlights 'our' values against 'their' values, manufactures crises where there are none and develops submissive disciples (Bass and Steidlmeier, 1999). Problems with the distinctions include the need for distinguishing between us (our values) and them (their values) being central for community and social identity, crises are not just objectively there but call for construction/framing (Grint, 2005) and the very idea of leadership - including TFL - means the subordinates taking much more of follower than leader positions, thus encouraging a form of submission.

People's 'true motives' are notoriously difficult to unpack - rather what is perhaps interesting is the vocabularies of motives (Mills, 1940). In the simple authentic and pseudo-transformational leadership divide we find the good vs the bad in a form that may fit the Sunday school better than commercial organizations, driven by profit motives and 
career interests. One major problem in the reasoning is its tautological and ideological nature: 'the assumption is that leadership must be something good. And in the event that it turns out to be bad, one might always argue that one did not witness the true concept of, let us say, 'transformational' or 'authentic' leadership. The concept is never to blame. Its beauty is always conceptually guaranteed because it is self-referentially true.' (Spoelstra \& ten Bos, 2011 p. 183)

Another key problem is that the enthusiasm of devoted followers may have little to do with Bass and Steidlmeier's idea of what is authentic and not. As Grint (2010) claims,

'there is preciously little evidence that admiring followers of Mao, Stalin, Hitler or Osama bin Laden followed their leaders because they were psychopaths . . . and much more evidence that they followed them because these followers assumed they were ethical.' (p 57)

If one looks at the key quality of TFL - that followers are motivated to do more than expected and be driven by the good of the collective/organization/society - then one could say that the bad persons mentioned by Grint outscore all business leaders, who appear as TFL midgets compared to the giants. But TFL and other leadership writers are typically very eager to distance themselves from non-positive characters, thus denying the complexities and ambiguities of 'real (organizational) life' (Jackall, 1988). One gets the feeling that Disney is more of an inspiration than corporate reality for many leadership academics.

Many authors emphasize the payoff of high-moral leadership arguing that high integrity and honesty can create efficiencies (Salam, 2000). However, it is probably better to see moral and efficiency as standing in a complex relationship, with no easy solutions for how 
to get world full of only good things together (Bolden et al, 2011). The large and expanding literature on authentic leadership and servant leadership preach extreme moral virtues of a saint like quality (Alvesson, 2011). In an often morally questionable business world we need the saviour, in the form of the saint like leader. The underlying assumption here is that financial and environmental scandals would avoidable if only we had the (morally) right leaders at the top, doing servant leadership or something else laudable (Sandjaya et al, 2008). Anything systemic such as institutions, capitalism, political (de)regulations, and consumer culture encouraging maximization of self-interest and greed are all downplayed.

\section{Ideology as facilitator of decontestation in leadership studies}

Contemporary leadership theories stress that effective leadership means a) powerful influence and is b) guided by high morality. The positive formula of leadership = power + morality accounts for the success story of contemporary leadership studies. This sounds really appealing and may be difficult to resist by people wanting a safe, harmonious world where good things go hand in hand, and the good and the strong can save us and/or offer the identification template for ourselves as leaders or leader-wannabees, possible also saving us from the messiness, ambiguities, immoralities and imperfections of the corporate world, including the power and politics that otherwise are seen as key elements in organizations.

One could thus make the claim that it is the ideological value of these leadership ideas that accounts for their success. That leadership studies are not, as is the case with management (and social science) more generally, ideologically neutral is not an original point (Alvesson 
\& Willmott, 2012; Gemmill \& Oakley, 1992; Knights \& Willmott, 1992; Trice \& Beyer, 1993). Social science involves studying value-laden phenomena of which the researcher is a part. The idea of studying effective leadership is hardly neutral. The ways we conceptualize and write about issues such as leadership do not just mirror external realities existing independently of our conceptions and writings about them, nor do we offer neutral tools for people to use as they see fit. Leadership research creates ways of seeing and valuing, normalizing subjects through suggesting idealized templates for being, supporting certain interests (normally those labelled 'leaders' rather than other people) and has some impact on how leadership behaviour is exercised - through publications and education (Foucault, 1980).

While large parts of leadership research are implicit in political and ideological bias - the strengthening of asymmetrical social relations and the construction of social relations alongside a leader/follower dichotomy and providing people with reassuring promises of good, effective leadership taking care of all problems - key parts of it are close to being openly propagandistic. This is the case for a lot of TFL and related streams, like authentic leadership. In-depth studies of organizations give a very different view on moral performances in management - here political behaviour and demands for being flexible in moral terms are salient (Jackall, 1988; Watson, 1994). Most leadership studies are, however, protected from close contact with reality as it can only to a modest degree be represented in questionnaire forms (or even in interviews with single persons supposed to be capable of being capable of telling how the leadership relations 'really' is like).

Representations of leadership practices emerge from ideologies as much as from the traits, values or motives of managers. Ideology influences consciousness, aspirations and an 
inclination to see and express coherence and harmony. But it has often a more ambiguous impact on the level of everyday practice. Whether people are particularly willing to be transformed by the leader, or insist on high wages, interesting job content and promotion possibilities that forces the transformation-inclined manager to engage also or mainly in transactions, is perhaps partly a matter of the organizational and occupational context. The majority of such contexts probably offer substantive material for clashes between leadership ideology and practice, but awareness of such confrontations seems to be rare in leadership studies - ideology as expressed in publications and education and also the espoused values and beliefs of managers is often disconnected from managerial practice in organizations (Alvesson \& Sveningsson, 2003). It is easy to miss that frequently leadership is event-driven rather than intention- and style-driven (Holmberg \& Tyrstrup, 2010; Lundholm, 2011).

Of course, leadership theory has always had a rather strong ideological undertone, but compared to earlier, fairly modest versions - focusing on traits, style, situatedness, leadermember exchanges etc (Yukl ,1981) - the now popular versions that have 'saved' leadership studies from its 70's and 80's depression are much more ideologically potent and provide leverage for ideas and claims of questionable intellectual value. The relationship between ideological and intellectual value is often negative as the former sacrifices empirical description and theoretical explanatory sharpness in favor of positivesounding (or possible demonizing) formulations, overemphasizing a harmonious state of affairs or reachable future. Leadership of the 'right' kind combines power, morality and farreaching influence over followers doing excellent work and being very satisfied. This is not caricature, but the picture conveyed by influential leadership research (Bolden et al, 2011). 


\section{Triggering the tautology trap: the role of empirical studies in TFL}

Thus, the academic leadership studies field not only adapts to and benefits from this appeal to fantasies about being extraordinary and remarkable, but also actively contribute to this. As an academic field, leadership studies follows its research logic, dominated by positivism (Antonakis et al, 2004; Mumford et al, 2009) and ideologically guided questions, with strong normative hints (e.g. about 'intellectual stimulation'), that allows for the merger of 'scientific procedure' and ideology. Many of the seemingly impressive results of leadership studies is rather an effect of this ideology being built into research designs, encouraging respondents (typically in one-source questionnaires) to report as if positive views to the manager go hand in hand with other positive things (fine climate, effectiveness, teamwork ...) characterising the unit the manager (leader) is leading.

It is claimed that there is rather strong support for TFL, e.g. 'A rich stock of studies suggest that TFL can be a very effective form of leadership' (Lindebaum \& Cartwright, 2010 p. 1320) and that 'numerous studies' 'have demonstrated the positive effects of TFL on various levels' (Fu et al, 2010 p. 225). As shown above, definitions tend to guarantee 'positive' outcomes, so empirical studies in TFL and other 'positive' theories tend to be exercises in confirmation bias and tautology. But what about 'the rich stock' of studies?

The predominant way of studying TFL (and leadership in general) is through the use of questionnaires (Diaz-Saenz, 2011). Sometimes one even gets the impression that leadership 'as such' - practices, interactions, relations - is of less interest for researchers than questionnaire filling behaviour. Responses to abstract formulations in questionnaires are usually remotely distanced from actions, events, feelings, relations, articulations of opinions, etc. emerging in every day life situations. That a person is asked to put an $\mathrm{X}$ in a 
particular response alternative from among the five or so possibilities in a questionnaire may say rather little of what or how that person feels or thinks or behaves, in the various situations he or she encounters and which the questionnaire tries to reflect (Alvesson, 1996). Two other reasons for why mainstream research is poor are the same-source bias, and tautology built into studies.

There is a large body of research on TFL and emotional intelligence relying on the same source, showing strong correlations. But when different sources (e.g. the manager and someone else, like a subordinate or the manager's own superior) are used, the EI selfratings of the managers and the TFL ratings of other people (their managers or subordinates) 'do not correlate significantly' (Lindebaum \& Cartwright, 2010). Also studies of LMX show low or moderate correlation between manager and subordinate ratings of the relationship (Cogliser et al, 2009; van Breukelen et al, 2006) as do research on self-other ratings (Fleenor, et al 2010).

Another problem with a large part of the leadership research is that includes an element of tautology - not only in theory, as addressed above, but also in research designs - and an inclination to avoid cognitive dissonance. Popular leadership studies are very much about marrying an ideology-laden leadership vocabulary with other forms of language use thus creating cognitive and linguistic coherence and avoiding dissonance. Thus, ideology frames empirical study in such a way that those studied tend to conform to the language convention mandated by the ideology in the first place. If a person agrees with statements such as 'my manager makes me proud to be associated with him/her' and 'provides advice to those who need it' he or she is probably inclined to put an $\mathrm{X}$ on a high score on 'overall work effectiveness of your unit' and the supervisor's effectiveness (Seltzer \& Bass, 1990), 
simple because it appears odd to report that one feels proud of a manager heading an ineffective unit.

Similar problems turn up in Conger et al (2000). Here charismatic leadership is expected to be positively related to a follower's sense of collective identity, perceived group performance and feelings of empowerment. The sample was asked to answer a 'questionnaire assessing a supervisor's behaviour' ( $\mathrm{p}$ 753). If a person tends to say that 'I hold him/her (the leader) in high respect', they may also agree with statements such as the leader is 'inspirational', 'influences others by developing mutual liking and respect' and 'often expresses personal concern'. And if they do, it would hardly come as a surprise that they tend to agree with statements like 'we see ourselves in the work group as a cohesive team' and 'I am keen on our doing well as an organization'.

When leadership is in focus, the intention, the act and the outcome are often coupled and placed in the same box, e.g. intellectual stimulation or idealized influence. This involves a lot of ambiguity around the leader's behaviour and the underlying influencing processes (Yukl 1999). This seems to be an accepted, but problematic, convention in 'mainstream'/dominant leadership studies. It encourages a tendency to produce in-built results and insensitivity to process and relational issues. For these reasons, and despite considerable efforts of TFL researchers to find efficient and reliable ways of using their questionnaires (Antonakis et al, 2004; Mumford et al, 2009), one can doubt how much all the empirical studies of TFL really tell, although there are a few more solid studies (e.g. Fu et al, 2010). We agree with the more technically focused, 'intra-paradigmatic' assessment of Van Knippenberg \& Sitkin (2013): 'the vast majority of studies have relied on a measurement approach for which there is overwhelming evidence of its invalidity' ( $p$ 45). 
The popularity of TFL and related streams can't be seen as simply reflecting their intellectual qualities, credible empirical support or practical relevance and value. What is actually the basis for the 'much greater optimism' (Bryman, 1996) amongst leadership researchers more recently? While we agree with Bryman that there are some positive theoretical developments, e.g. management of meaning (Ladkin, 2010; Sandberg \& Targama, 2007; Smircich \& Morgan, 1982) and more relational and dialectic approaches (Collinson, 2006; Uhl-Bien, 2006) that are interesting, these are hardly accountable for broadly shared feelings of the improved position of leadership studies, based on the enthusiasm of much more heroic views such as transformational, charismatic and authentic leadership.

\section{Remedies: re-contesting and de-ideologizing leadership research}

In their fundamental critique of TFL, Van Knippenberg \& Sitkin (2013) make short shrift of both concepts and empirical work and suggests that TFL people need to start from scratch. We agree with the critique, but see the fundamental issue as more profound than matters of conceptual precision and empirical rigour. TFL and, as this is the major approach and vehicle lifting the field of leadership studies more generally, have boomed very much due to its ideological appeal. Also many seemingly 'progressive' versions of leadership, emphasizing constructions, relations and 'post-heroic' elements draw upon and benefit from this broad ideological appeal. The seductive power of TFL, within leadership studies as well as business and society as a whole, in combination with the eagerness to move out of the disappointment of the field in the 1980's have lead to the acceptance and celebration of poor scholarship on a broad scale. Ideology, positive portrayals of what exist 
and what should be done enchant audiences and bracket the critical and intellectual orientations that normally is supposed to guide academic work and the assessment of theory and empirical studies. In the case of TFL, ideology has triumphed over intellectual concerns.

Nevertheless, values, world-views and specific labels always guide studies in such a way that certain interests, institutions and sets of ideas are reproduced/challenged or reinforced/weakened. This cannot be avoided or marginalized through 'objectivity' or, as we have shown, by adhering to established methodology and theory. What we can do is to work with ideology in far better ways than is done by the majority of researchers in the 'successful' leadership field - a field easily dismissed as mainly ideological. Below we offer a framework, for moves towards a 'de-ideologization' of LS - and also potentially for other areas:

- Avoid strongly positive and persuasive terms. Find more neutral/less seductive ones and, when difficult, indicate the potential negative side of also positive-sounding words.

- Minimize and problematize the setting up of the good vs the bad. Apart from steering away from 'pure goodness' (and pure badness) acknowledge that the seemingly good may go hand in hand with the less good: the fundamental problem of cognitive dissonance. Point at the imperfections of reality, where the good and the bad often may go hand in hand or ambiguities rule over clear styles, values, practices or outcomes

- Avoid overpacking leadership (and other vocabularies) with performative verbs and separate intention, practice and outcome. This includes being careful with tautologies. 
- Be careful about relying on informants producing data with a strong ingredient of "moral storytelling", i.e. presenting themselves and their ambitions and accomplishments in explicit or subtle self-celebrating terms. Source-critique and caution in taking empirical material from interviews and questionnaires at face value is vital.

- Use language (in particular in writing) so there is awareness that there may be other, possible better ways, of constructing/representing the subject matter. Challenge, at least occasionally, favored language and point at alternative vocabularies.

It is important to be clear that counter-ideology does not really offer a useful alternative. Consider, for example Gemmill \& Oakley (1992) who provides the flip side of the coin in arguing that leadership is a social pathology. For them leadership is a social myth that propagates alienation, reification, learned helplessness and other pathologies, in the name of anxiety suppression and consensus formation. Their argument is that leadership operates as an ideologically charged sledgehammer that is used to smash autonomy and collaborative action, and to provide cover for power grabs from particular social elites, such as executives and other managerial groups. Again, highly loaded terms such as alienation, pathology and deskilling are mobilized; a Manichean worldview is constructed, although reversed in the sense that leadership is bad and everything else is good; all types of authority is conflated into leadership; the paper constructs a straw person, with no empirical support; and there is no space for the play of opposites and irony.

Although Gemmill \& Oakley's argument is thoughtful, and can be viewed as a useful corrective to the gushing of leadership proponents, they end up with nowhere to go. This is particularly clear in the latter parts of their argument where they attempt to experiment with 
new paradigms for the understanding of the leadership phenomena. After their previous demolition job of the concept, the attempts to push in more constructive directions appear futile. The problem here is that the counter-ideological argument is in itself too ideologically charged to allow for constructive engagements with the concept. It is too categorical to allow for fruitful experimentation with new ideas.

\section{De-ideologizing leadership studies: two illustrations}

Moving on to our major theme - popular LS - we will now illustrate how ideologically saturated texts can be de-masked and de-ideologized. Zhu et al (2013) argue that two basic types of trust mediate the relationship between transformational leaders and followers: affective trust and cognitive trust. Affective trust emerges when followers develop a strongly personal, intimate, and emotional bond to the leader. Cognitive trust, on the other hand, emerges at a distance, where the follower makes an assessment of the leader's character, based on the leaders performance as viewed from the 'outside'. Zhu et al finds that although affective trust is an unequivocal social good, cognitive trust is more problematic and associated to underperforming employees. Hence, they conclude, that trust is not always good from a managerial perspective; managers would benefit from research the kind of trust that is deployed, and basically try to minimize cognitive trust while maximizing affective trust.

Apart from drawing on the inherently Manichean TFL worldview, with its strong focus on loaded and overpacked vocabulary and moralizing storylines, the paper also set up a 'good' kind and a 'bad' kind of trust. Good trust comes from vibrant, emotional and personal relationships, while bad trust comes from cool, distant and calculative relationship, fermenting social loafing and free-riding on the capable and competent transformational 
leader. The strong ideological framing of the paper makes the interpretation of the data almost self-evident. Trust might look double-edged at first glance, but not when properly unpacked.

However, a less ideological interpretation of Zhu et al's (2013) data is that they capture more of how relationships are characterized by reciprocity and patronage. Since the job performance evaluation is based on supervisor's subjective reports, it is not surprising that they have stronger and more personal and intimate relationships with people they deem high performing. This perhaps makes the leaders into less of transformational leaders, who after all perhaps would view low performers as excellent turn around targets for transformational leadership, but renders them more like humans: malleable and driven by shared interests. It also shows how dynamics of inclusion and exclusion drives human interaction and, arguably, leadership practices.

In a more schematic form, Zhu et al would have benefitted from

- Not immediately accepting transformational leaders awesome capacities, and allow for more nuance in what drives leaders and followers

- Assuming that 'affective' and 'cognitive' trust may signify deeper relationship issues and discrepancies that are worthy of including in the interpretation. For example, 'affective' trust may be a result of long term patronage and collaboration, while 'cognitive' trust may indicate excluded, marginalized and stigmatized groups and individuals.

- Having a skeptical or at least more open attitude towards the managerial evaluation of job performances. Managers hardly always evaluate subordinates on objective and fair grounds; people with low evaluations might be potential whistleblowers or dissenters. 
- Allow for the tension between various forms of trust to be explored more deeply, and allow for the irony that some forms of trust might lead to low performance to play out for longer

- Not necessarily going for saving the concept of transformational leadership but rather using the data to question the basic tenets of transformational leadership: why do transformational leaders develop strong ties of trust with people that are already highperforming? Perhaps what may appear as 'transformational' is an outcome of subordinates being 'high-performing'? What are the barriers for followers that are excluded from developing affective trust to leaders?

Ideology is of course not only afflicted to TFL and TFL-based studies. Consider for example Cunliffe \& Eriksen (2011), who address "relational leadership". This is "an inherently moral and dialogical practice" (p 1428) and is in the entire paper presented in uplifting ways, e.g. through terms like "collaboration, empathy, trust, empowerment" (p 1430). The authors claim, based on an empirical study that "four main conceptual threads run through relational leadership: leadership is a way of being in the world, encompasses working out, dialogically, what is meaningful with others, means recognizing that working through differences is inherently a moral responsibility; and involves practical wisdom" ( $\mathrm{p}$ 1433). The paper is full of expressions like "relationally-responsive dialogue", "the need to be respectful, establish trust, and for people to be able to "express themselves", "to treat people as human beings, of having a 'heart', appreciating others, and encouraging them to grow and learn from each other" (p 1433). While all the people interviewed, most of them managers, expressed their ideals and practices in line with these themes, others, not included in the study, were occasionally referred in less flattering term. The paper acknowledges that there may be a "myriad of seemingly conflicting interests" but this appears to be handled without much 
problems through "understanding that relationships are intricately entwined, embedded, constantly shifting and unique as we interact with others" by "relational leaders (who) are open to the present moment and to future possibilities" ( $\mathrm{p} 1437)$.

Thus, the paper is drawing on strongly rhetorically loaded concepts; setting up the good relational leader against the bad heroic one, the dialogic (talking with people) vs monologic discourse (silencing and marginalizing); conflating somewhat different phenomena (e.g. relational integrity); rely heavily on informants describing themselves in very positive ways; showing no signs on engaging with irony or breakdowns in understanding, but advocates relational leadership as a superior mode of leading; and assuming and implicitly claiming that all the good things go hand in hand and there are no negative aspects of all this worth mentioning.

A less ideological re-imagining of their argument and issues to be considered in empirical inquiry might look something like this:

- The 'relational leader' pay much attention to establishing good human relationships, which may occasionally lead to complicated social relations with high expectations on an almost quasi-therapeutical quality and some neglect of technical, economical and administrative concerns. The costs of "full-fledged" relationality need to be considered.

- Relational qualities and orientations may range broadly and many of these may not co-exist. Relationality may include alignment of interest and meanings, but relational qualities may be perceived quite differently, involving conflict, distance or disinterest. The relational is perhaps not only something positive. Relational and integrity may be 
integrated or dis-connected. Integrity may call for some distancing and downplaying of empathy and responsiveness. Nepotism and favoritism may be part of relationality.

- The informants in the study speak of themselves, their motives and practices in generally very positive terms. Others are referred to in less flattering ways. E.g. "we listened to everybody" (Cunliffe \& Eriksen, 2011 p. 1441) while "I have heared horror stories where the FDS misrepresented the facts" ( $\mathrm{p}$ 1440). It may be true that the people interviewed are "better" than others - within the framework of the paper but the accounts may be an outcome of moral story-telling and self-serving bias. Some critical assessment - source critique - is motivated.

- Considering alternative vocabularies than the preferred one is a way of not being caught in a particular ideological commitment. "Understanding the importance of relational integrity: respecting and being responsive to differences, being accountable to others, acting in ways that others can count on us“ ( $\mathrm{p}$ 1444) could be reformulated in less celebratory ways, e.g.: accepting (rather than work actively with) variations in opinions, meanings and moralities, adapt to a high degree to the demands and judgments of others, refrain from the creation of shared meanings.

- Ideals easily clash and needs to be highlighted and not avoided. Yes, it is fine with "relational leaders (who) are open to the present moment and to future possibilities", but sometimes closure is motivated: focus, agenda-setting, direction and avoidance of over-stimulation may be beneficial for getting the work done.

Of course, following a de-ideologization route would create considerable problems for LS. Those neat results "proving" the value of transformational leadership, appealing reasoning of the value of authenticity, emotional intelligence, relationality, or the pathologies of 
leadership, for that matter, would be undermined. The apparent relevance and value for practitioners wanting to have positive news and an appealing formula for good leadership would be reduced. The LS community may be back into bewilderment and depression.

Ideology has its advantages and the attractions are strong. We can not eliminate ideology, but a social science worth its name need to be committed to an intellectual agenda and work hard to avoid the temptations of seductive terms and formulations, tautologies and a world view where some things are simply good and go hand in hand with other good things without anything disturbing the rosy ideal. There is plenty of space for interesting, challenging LS navigating around ideological peaks, although this calls for serious re-considerations of what the LS field is up to.

\section{Conclusion}

The basic story of progress in organization studies, and social science in general, is straightforward. Worthy ideas consist of coherent constructs supported by empirical evidence, unworthy ideas does not, and the difference is decided through rigorous research protocols. In actual practice, things are much more muddled. Some of this is because almost every word of the one sentence outline of scientific progress above is contested one way or another. There is no or little consensus on what constitute ideas, empirical evidence, rigorous research and so on. And maybe the story is problematic, too.

Despite the lack of clarity, more or less cohesive research areas emerge, and can arguably be understood as being successful in this respect. In this paper we have suggested that such success can be explained by other factors than those suggested by the standard story of scientific progress. It is broadly claimed, by people in leadership studied, that the field over 
a fairly short period moved from being a sad state to one of optimism and progress, from a sense of failure to self-confidence and success. We have indicated that this is not selfevidently explained by good and better ideas and results, but could be seen as a mystery calling for looking for non-obvious ways of explaining this.

More specifically. this paper makes two contributions. The first is to show the ideological nature through which leadership studies are carried out. A lot of leadership research is about the detailed investigation of specific theories, aiming to add to the literature. The underlying ideological nature of the entire enterprise tends to be neglected. Few studies take a deep and close look at the subject matter. There is a lot of black-boxing of what actually happens in leadership, defined as but seldom directly studied as an influence process carried out in interaction within a specific context. In-built ideological tendencies and tautologies account for many of the results: good things go together in a harmonious whole. Language rules, social norms and the inclination to avoid cognitive dissonance in many cases facilitate predictable 'results'.

The paper shows how appealing, but intellectually unimpressive images put strong imprints on influential versions of leadership theory. Spoelstra \& ten Bos (2011) argue that 'all leadership necessarily needs idolization, precisely because the sublime object of leadership is constituted through idolization' ( $p$ 195). We claim that this idolization is much stronger in the leadership approaches leading the field's move into its current, seemingly happy and optimistic state. The complexities of managerial work and profit-driven, bureaucratic and sometimes not so Sunday school like organizations are not supposed to ruin this cosy picture. 
A second contribution concerns the 'theoretical-methodological' implications for leadership studies. The paper provides a guideline for scholars of leadership to resist ideological and normative appealing ideas and formulations and research designs protecting the researcher from deviations from a harmonious world of the good (TFL, authentic, servant, relational, Level 5) leadership leading to good results through the good leader making people into followers and turning these into (morally and effectively) good workers. A qualified understanding of leadership and contribution to valuable knowledge in an imperfect world, with imperfect people is arguably much better accomplished by researchers going to the field of ('ordinary') workplaces and manager-subordinate interactions rather than consulting ideologically soaked holy texts. The field may be far less glamorous and comforting to draw inspiration from, but leadership researchers eager to score higher intellectually than ideologically need to take a serious interest in the real world - beyond the sphere of questionnaire filling and interview responding behaviour, saying more about available leadership ideologies than specific leadership practices and relations.

To put it bluntly, to a significant degree leadership studies have followed a success formula where ideology + tautology + ignorance $=$ popular leadership ideas. This is not to say that there is not promising and interesting work in leadership studies. We partly agree with Parry \& Bryman (2006) about progress in variations and developments (attribution theory, relational leadership ideas, management of meaning, critical leadership studies). And we would not necessarily deny that TFL could be inspirational for managers and sometimes lead to positive effects in organizations. Still, there is a strong imprint of ideology and wishful thinking that is central in the move to recent 'success' in leadership studies. Even 'non-heroic' views of leadership are influenced by, and benefit from, the general 
ideological appeal of 'mainstream' leadership. Promoting ideology is obviously very different from promoting new and exciting research ideas, but, although ideology-free studies are impossible, texts can be 'ideologically' disruptive and unruly rather than reinforcing comforting thought patterns. If unchecked, research becomes subsumed to ideological closure, ultimately only offering a claustrophobic chorus of conformism around the significance and positive nature of the 'right' kind of leadership. Against this we need research that is seriously committed to efforts to de-ideologize leadership.

\section{References}

Alimo-Metcalfe, B \& Alban-Metcalfe, J (2001) The development of a new transformational leadership questionnaire. Journal of Occupational and Organizational Psychology, 74, 1, 1-27

Alvesson, M (1987) Organization Theory and Technocratic Consciousness. Berlin/New York: de Gruyter

Alvesson, M. (1996) 'Leadership studies: from procedure and abstraction to reflexivity and situation', Leadership Quarterly, 7(4), 455-485.

Alvesson, M (2011) The leader as saint. In M.Alvesson \& A. Spicer (eds), Metaphors we lead by. Leadership in the real world Metaphors we lead by. London: Routledge. Alvesson, M. (2013) The Triumph of Emptiness. Oxford: Oxford University Press. Alvesson, M. \& Karreman, D. (2011) Theory Development and Qualitative Research. London: Sage

Alvesson, M. \& A. Spicer eds. (2011), Metaphors we lead by: Leadership in the real world. London: Routledge. 
Alvesson, M. \& A. Spicer (2014) Critical perspectives on leadership. In Day, D. (ed.) Oxford Handbook of Leadership in Organizations. Oxford: Oxford University Press.

Alvesson, M. \& S. Sveningsson (2003), The good visions, the bad micro-management and the ugly ambiguity: Contradictions of (non-)leadership in a knowledge-intensive company. Organization Studies, 24 (6), 961-988.

Alvesson, M \& Willmott, H (2012) Making Sense of Management. A Critical introduction. London: Sage.

Andriessen, E. \& P. Drenth. (1984). 'Leadership: theories and models'. In P. Drenth, H. Thierry, P. J. Willems and C. J. de Wolff (eds). Handbook of Work and Organizational Psychology. Vol. 1. Chichester: Wiley.

Antonakis, J., Schriesheim, C. A., Donovan, J. A., Gopalakrishna-Pillai, K., Pellegrini, E. K., \& Rossomme, J. L. (2004). Methods for studying leadership. The nature of leadership, 48-70.

Avolio, B. J., Sosik, J. J., Jung, D. I., \& Berson, Y. (2003). Leadership models, methods, and applications. Handbook of psychology..

Barley, S. R., \& Kunda, G. (1992). Design and devotion: Surges of rational and normative ideologies of control in managerial discourse. Administrative Science Quarterly, 363-399.

Bass, B. M. \& P. Steidlmeier (1999), Ethics, character, and authentic transformational leadership behavior. Leadership Quarterly, 10, 181-217.

Bernstein, R. J. (1983). Beyond objectivism and relativism: Science, hermeneutics, and praxis. University of Pennsylvania Press.

Blom, M \& Alvesson, M (2014) Leadership on demand. Followers as initiators and inhibitors of managerial leadership. Scandinavian Journal of Management, 30: 344357 
Bolden, R., Hawkins, B., Gosling, J., \& Taylor, S. (2011). Exploring leadership: individual, organizational, and societal perspectives. Oxford University Press..

Bryman, A. (1996). 'Leadership in organizations'. In S. Clegg, C. Hardy and W. Nord (eds) Handbook of Organization Studies. London: Sage.

Bryman, A. (2011) Research methods in the study of leadership. In Bryman, A. et al (eds) The SAGE Handbook of Leadership. London: Sage.

Burns, J. M. (1978) Leadership. New York: Harper \& Row.

Caza, A \& Jackson, B (2011) Authentic leadership. In Bryman, A. et al (eds) The SAGE Handbook of Leadership. London: Sage.

Cogliser, C., Schriesheim, C., Scandura, T. \& Gardner, W. (2009) Balance in leader and follower perceptions of leader-member exchange: relationships with performance and work attitudes. Leadership Quarterly, 20, 452-465.

Collins, J. C. (2001). Good to great: Why some companies make the leap--and others don't. Random House.

Collinson, D. (2005). Dialectics of leadership. Human Relations, 58, 1419-1442.

Collinson, D (2006) Rethinking followership: a post-structural analysis of follower identities. Leadership Quarterly, 17, 179-189

Collinson, D. (2011). Critical leadership studies. The Sage handbook of leadership, 181-194.

Conger, J, Kanungo, R \& Menon, S (2000) Charismatic leadership and follower effects. Journal of Organizational Behaviour, 21: 747-767

Cunliffe A and Eriksen M (2011) Relational leadership. Human Relations 64, 14351449. 
Czarniawska-Joerges, B. (1988). Ideological control in nonideological organizations. New York: Praeger.

Díaz-Sáenz, H. R. (2011). Transformational leadership. The SAGE handbook of leadership, 299-310..

Fairhurst, G. T. (2001), Dualisms in leadership research. I: F. Jablin \& L. L. Putnam (red.), The new handbook of organizational communication: Advances in theory, research, and methods. Thousand Oaks, CA: Sage, 379-439.

Fairhurst, G. T (2007), Discursive leadership: In conversation with leadership psychology. Thousand Oaks, CA: Sage.

Fleenor, J. et al (2010) Self-other rating agreement: a review. Leadership Quarterly $21,1005-34$

Fleming, P \& Mandarini, M (2009) Towards a workers' society? New perspectives on work and emancipation. In Alvesson, M , Bridgman, T., \& Willmott, H. (eds) Oxford Handbook of CMS. Oxford. Oxforud University Press.

Foucault, M. (1980) Power/Knowledge. New York:Pantheon.

Freeden, M. (2003). Ideology: A very short introduction. Oxford: Oxford University Press.

Fryer, M. (2011) 'Facilitative leadership: Drawing Habermas' model of ideal speech to propose a critically sensitive way to lead', Organization, 19, 25-43.

Fu, P. P., Tsui, A. S., Liu, J., \& Li, L. (2010). Pursuit of whose happiness? Executive leaders' transformational behaviors and personal values. Administrative Science Quarterly, 55(2), 222-254.

Gemmill, G. and Oakley, J. (1992) 'Leadership: An Alientating Social Myth', Human Relations, 45(2), 113-129. 
Grint, K (2005) Problems, problems, problems: the social construction of 'leadership'. Human Relations, 58 (11), 1467-94

Grint, K (2010) The sacred in leadership: separation, sacrifice and silence. Organization Studies, 31, 89-107.

Gronn, P. (2002). Distributed leadership as the unit of analysis. Leadership Quarterly, $13,423-451$.

Hartley, J. F. (1983). Ideology and organizational behavior. International Studies of Management \& Organization, 7-34.

Härtel, C \& Ashkanasey, N (2011) Healthy human cultures as positive work environments. In $\mathrm{N}$ Ashkanasy, C Wilderom \& $\mathrm{M}$ Peterson (eds) Handbook of Organizational Culture and Climate. (2nd ed) Thousand Oakes: Sage

Hartnell, C.\& Walumbwa, F. (2011) Transformational leadership and organizational culture: toward integrating a multilevel framework. In N Ashkanasy, C Wilderom \& M Peterson (eds) Handbook of Organizational Culture and Climate. (2nd ed) Thousand Oakes: Sage

Heifetz, R \& Laurie, D (1994) The work of leadership. HBR, Jan-Feb 1997, 124-134. Helsing, D., \& Howell, A. (2014). Understanding Leadership from the Inside Out Assessing Leadership Potential Using Constructive-Developmental Theory. Journal of Management Inquiry, 23(2), 186-204.

Holmberg, I., \& Strannegård, L. (2005). Leadership Voices: The Ideology of 'The New Economy’. Leadership, 1(3), 353-374.

Holmberg, I. \& Tyrstrup, M. (2010) Well then -what now? An everyday approach to managerial leadership. Leadership 6, 353-372. 
Howell, J. \& Shamir, B. (2005) The role of followers in the charismatic leadership process: relationships and their consequences. Academy of Management Review, 30, 96-112.

Jackall, R. (1988) Moral Mazes. The World of Corporate Managers. New York: Oxford University Press.

Jackson, B. \& K. W. Parry (2008) A very short, fairly interesting and reasonably cheap book about studying leadership. London: Sage.

Kairos Futures/Chef (2006) Bäst på allt och aldrig nöjd. ('Best on everything and never pleased'). Stockholm

Kelly, S. (2008) 'Leadership: A Categorical Mistake?', Human Relations, 61, 763 782.

Kets de Vries, M (1980) Organizational Paradoxes. London: Tavistock.

Kets de Vries, M (1994) The leadership mystique. Academy of Management Executive. 8, 73-89

Knights, D. \& H. Willmott. (1992). 'Conceptualizing leadership processes: a study of senior managers in a financial services company'. Journal of Management Studies. 29, $761-782$.

Kunda, G. (1992). Engineering culture: Control and commitment in a high-tech corporation. Temple University Press.

Ladkin, D. (2010), Rethinking leadership: A new look at old leadership questions. Cheltenham: Edward Elgar.

Lakomski, G (2005) Managing without leadership. Amsterdam: Elsevier Latham, S. D. (2014). Leadership Research An Arts-Informed Perspective. Journal of Management Inquiry, 23(2), 123-132. 
Liden, R. \& Antonakis, J. (2009) Considering context in psychological leadership research. Human Relations, 62, 11:1587-1605.

Lindebaum, D \& Cartwright, S (2010) A critical examination of the relationship between emotional intelligence and transformational leadership. Journal of Management Studies, 47 (7):1317-1341.

Lundholm, S. (2011). Meta-managing: A study on how superiors and subordinates manage their relationship in everyday work (Doctoral dissertation, Lund University).

Meindl, J (1995) The romance of leadership as a follower-centric theory: a social constructionist approach. Leadership Quarterly 6, 329-341.

Mills, C W (1940) Situated action and the vocabularies of motives. Am. Sociological Review, 5, 904-913

Mumford, M., Scott, G., Gaddis, B. \& Strange, J. (2002) Leading creative people: Orchestrating expertise and relationships. Leadership Quarterly, 13, 705-750.

Mumford, M. D., Friedrich, T. L., Caughron, J. J., \& Antes, A. L. (2009). Leadership research: Traditions, developments, and current directions. The Sage handbook of organizational research methods, 111-127. Ospina S \& Sorenson G (2006) A Constructionist lens on leadership: Charting new territory. In: Goethals $G$ and Sorenson G (eds) The quest for a general theory of leadership. Cheltenham: Edward Elgar.

Palanski, M \& Yammarino, F (2009) Integrity and leadership: a multi-conceptual framework. Leadership Quarterly 20, 405-420.

Parry, K. \& A. Bryman (2006), Leadership in organizations. In: S. Clegg, C. Hardy \& W. Nord (red.), Handbook of organization studies. (2 ed.) London: Sage, 447-478. Pearce, C \& Conger, J (eds). (2003) Shared Leadership: Reforming the Hows and Whys of Leadership. Thousand Oaks, CA: Sage 
Salam, S (2000). Foster trust through competence and integrity. In Locke, E (ed) Handbook of Principles of Organizational Behaviour. Oxford: Blackwell.

Sandberg, J. \& Targama, A. (2007) Managing Understanding in Organizations. London: Sage.

Sendjaya, S., Sarros, J. C., \& Santora, J. C. (2008). Defining and measuring servant leadership behaviour in organizations. Journal of Management Studies, 45, 402-424.

Sashkin, M (2004) Transformational leadership approaches: a review and synthesis. In Antonakis, J et al (eds) The Nature of Leadership. Thousand Oakes: Sage Sashkin, M \& Garland H. (1979) Laboratory and field research on leadership: Integrating divergent streams. In J Hunt \& L Larson (Eds). Crosscurrents in Leadership. Carbondale and Edwardsville: Southern Illinois University Press.

Schein, E H (1985) Organizational Culture and Leadership. San Francisco: JosseyBass

Seltzer, J. \& B. Bass. (1990). 'Transformational leadership: beyond initiation and consideration.' Journal of Management. 16, 693-703.

Smircich, L. \& G. Morgan. (1982). 'Leadership: the management of meaning'. The Journal of Applied Behavioural Science. 18, 257-273.

Spoelstra, S. \& ten Bos, R. (2011) Leadership, in Business Ethics and Contemporay Philosophy. Cambridge: Cambridge University Press.

Tourish, D \& Pinnington, A (2002) Transformational leadership, corporate cultism and the spirituality paradigm. An unholy trinity in the workplace? Human Relations $55,147-152$.

Trice, H. M. \& J. M. Beyer (1993), The culture of work organizations. Englewood Cliffs, NJ: Prentice-Hall.

Uhl-Bien, M. (2006) Relational leadership theory: Exploring the social processes of leadership and organizing. The Leadership Quarterly, 17, 654-676. 
Uhl-Bien M, Marion R \& McKelvey B (2007) Complexity leadership theory: shifting leadership from the industrial age to the knowledge era. Leadership Quarterly 18, 298318.

Uhl-Bien, M. \& R. Pillai (2007) The romance of leadership and the social construction of followership. In: B. Shamir, R. Pillai, M. Bligh \& M. Uhl-Bien (red.), Followercentered perspectives on leadership: A tribute to the memory of James $R$. Meindl. Greenwich, CT: Information Age Publishing, 187-209.

van Breukelen, W, Schyns, B \& La Blanc, P (2006) Leader-member exchange theory and research: accomplishments and future challenges. Leadership, 2, 297-316

Van Knippenberg, D. \& Sitkin, S. (2013) A critical assessment of charismatictransformational leadership. Academy of Management nnals. 7, 1-60.

Vangen, S., \& Huxham, C. (2003). Enacting leadership for collaborative advantage: Dilemmas of ideology and pragmatism in the activities of partnership managers. British Journal of Management, 14(s1), S61-S76.

Watson, T. (1994) In Search of Management. London: Routledge.

Western, S. (2008) Leadership: A Critical Text. Sage, Thousand Oaks.

Yukl, G. (1981) Leadership in Organizations. Englewood Cliffs, NJ: Prentice-Hall.

Yukl, G. (1989) 'Managerial leadership: a review of theory and research'. Journal of Management. 15, 251-289.

Yukl, G (1999) An evaluation of conceptual weaknesses in transformational and charismatic leadership theories. Leadership Quarterly 10, 285-305.

Zhu, W., Newman, A., Miao, Q., \& Hooke, A. (2013). Revisiting the mediating role of trust in transformational leadership effects: Do different types of trust make a difference?. The Leadership Quarterly, 24(1), 94-105 
